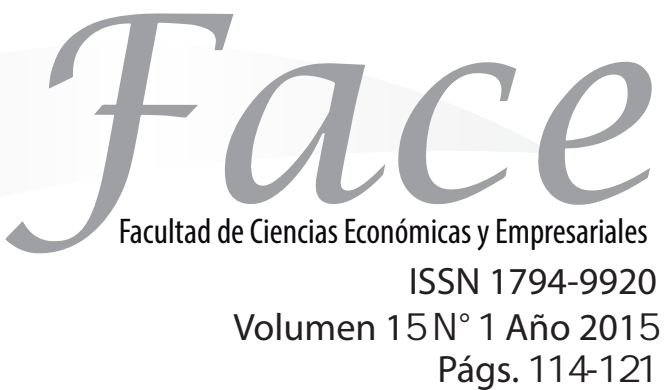

\title{
EL PAPEL DEL PATROCINIO Y EL AMBUSH MARKETING, EN LA CONSTRUCCIÓN DE MARCA
}

Diana María López Célis *

Fecha de Recepción: 2 de febrero 2015

Fecha de Aprobación: 30 de Mayo 2015

Resuren

En este artículo, a través de una investigación exploratoria con alcance cualitativo, utilizando fuentes secundarias y entrevistas con expertos, se profundizará en dos herramientas usadas en las estrategias de comunicación; el patrocinio y el ambush marketing. Teniendo en cuenta que en el patrocinio, la marca tiene exclusividad y obviamente requiere de una mayor inversión, se ha pensado que es mucho más efectivo que el ambush marketing, pero se encuentra que más allá del uso de cualquiera de estas dos herramientas en las estrategias de comunicación, tiene una gran incidencia la forma o contenido de la comunicación y buscar asociar con la marca, estereotipos que se identifiquen con el consumidor.

PALABRAS CLAVE: Patrocinio, Ambush marketing, Marca, Imitación, Estereotipo.

\footnotetext{
*Magíster en Psicología. Especialista en Psicología del Consumidor. Subdirectora de Investigaciones en Starcom Colombia. Gerente de oficina en Zenith Quito, Lider cuenta de Nestlé. Catedrática en las Universidades; Central, Javeriana, Piloto y Konrad Lorenz. Contacto: diana.lopez@utadeo.edu.co
} 


\section{THE ROLE OF SPONSOSHIP AND AMBUSH MARKETING IN BRAND BUILDING Abstrat}

The present article, through an exploratory research with qualitative scope, using secondary sources and interviews with experts, concentrated on two tools used in communication strategies; sponsorship and ambush marketing. Taking into account that in sponsorship the brand has exclusivity and obviously requires greater investment, it is thought to be more effective than ambush marketing, however, beyond the use of any of these tools in communication strategies, the form and content of the communication has a greater impact when associated with consumer brand and stereotypes.

KEYWORDS: Sponsorship, Ambush Marketing, Brand, Imitation, Stereotype.

\section{O PAPEL DO PATROCÍNIO EAMBUSH MARKETING NA CONSTRUÇÃO DE MARCA \\ Resuma}

Neste artigo, através de pesquisa exploratória com alcance qualitativo, usando fontes secundárias e entrevistas com especialistas, se aprofundou em duas ferramentas utilizadas em estratégias de comunicação; o patrocínio e o ambush marketing.Tendo em conta que no patrocínio, a marca tem exclusividade e obviamente requer de maior investimento, pensou-se que é muito mais eficaz que o ambush marketing, no entanto, além do uso de qualquer destas duas ferramentas em estratégias de comunicação, a forma e o conteúdo da comunicação tem maior impacto quando associado a estereótipos e a marca do consumidor.

Palavras-Chave: Patrocínio, Ambush Marketing, Brand, Imitação, estereótipo. 


\section{Introducción:}

En este estudio exploratorio, se presentará el proceso de aprendizaje que realizan los seres humanos para interiorizar o codificar las marcas y cómo el patrocinio y el ambush marketing como estrategias de comunicación; más alla de la inversión que requiere cada una de estas estrategias; donde el patrocinio, requiere una inversión mucho más alta con respecto al ambush marketing, el impacto que logre cada una de estas estrategias, en los procesos de aprendizaje de marca, depende más del contenido de la comunicación y la selección de los estereotipos que se manejen.

\section{Marco teórico:}

\subsection{El Proceso de Aprendizaje de las Marcas.}

Resulta difícil hablar de una definición definitiva acerca de cómo aprenden los consumidores o que tenga una aceptación general, podríamos enunciar diferentes autores y sus respectivas definiciones, pero un concepto en el cual coinciden la mayoría de los autores; esque el aprendizaje es un proceso, para lo cual podemos citar la definición que realiza Shiffman(2010), en su libro comportamiento del consumidor "proceso mediante el cual los individuos adquieren el conocimiento y la experiencia, respecto de compras y consumo, que luego aplican en su comportamiento futuro".

Un proceso que requiere de la experiencia, la cual se adquiere de forma intencional o incidental. Existen diferentes teorías que explican cómo los individuos en general, se apropian de las experiencias o aprenden, donde podemos mencionar modelos como; el condicionamiento clásico, el condicionamiento instrumental y aprendizaje por modelamiento y emulación.

Tomaremos brevemente, las definiciones realizadas por Shiffman (2010), para cada uno de estos procesos de aprendizaje

1. Condicionamiento Clásico: Aprendizaje por asociación entre eventos.

2. Condicionamiento Operante: El aprendizaje ocurre a través de un procesode ensayo y error.
3. Modelamiento:Se le denomina así, al reforzamiento que se realiza antes de que se presente la conducta deseada por parte de los consumidores, el cual incrementa la probabilidad de que el consumidor se comporte de la manera deseada.

4. Emulación u observación de estereotipos: Es el proceso por el cual los individuos aprenden comportamientos al observar la conducta de otros y las consecuencias de tal comportamiento.

Es importante analizar este proceso; puesto que el aprendizaje del consumidor, persigue generar hábitos de consumo y lealtad de marca. En línea con la definición de Shiffman (2010),cuando el consumidor replica un comportamiento en el futuro, ante una situación idéntica o similar, es porque se ha dado el aprendizaje; es decir, lo ha interiorizado y si repite la conducta de compra, habrá generado lealtad por la marca; entendida la marca como el nombre, término, diseño o la combinación que sirve para identificar el producto de un vendedor o fabricante y diferenciarlo de la competencia, de acuerdo a la definición deLamb (2011) y representa uno de los más grandes capitales de la empresa.

La recompra se da, cuando el producto satisface las necesidades del consumidor y existe repetición constante del estímulo (frecuencia), a través de la comunicación.

La comunicación, es la herramienta que ayuda a informar, persuadir y recordar las marcas en el momento de tomar la decisión por una específica; por tanto, la comunicación formal e informal inciden en el proceso de aprendizaje,la comunicación informal se puede experimentar desde muy temprana edad con la familia y a medida que se va dando el proceso de socialización; la comunidad, grupos sociales, grupos de referencia, líderes de opinióny a través de la comunicación emitida por las organizaciones con ánimo o sin ánimo de lucro, que constituye las fuentes formales de información. Los líderes de opinión como parte de la comunicación informal,entran a formar parte de las imágenes y el repertorio conductual de los individuos, a través del aprendizaje por imitación.

¿Pero a quién se imitará?; es decir,¿cómo se dará este proceso de aprendizaje por imitación, en el proceso de adopción de las marcasen los consumidores?, se deben elegir grupos o líderes de opinión, cuyas creencias o actitudes coincidan o sean 
respetadas y consideradas dignas de imitar yser apropiadas por los individuos. Este proceso de aprendizaje es muy bien aprovechado por las diferentes empresas, a través de la comunicación formal.

En mercadeo y más exactamente al manejar el mix de marketing; en la variable de comunicación, la asociación del producto con un grupo, personaje, acontecimiento especial o causa social; hace posible construir o modificar las actitudes respecto a una compañía, producto o marca, indicando las relaciones que guardan entre sí.

Los publicistas reconocen la importancia del aprendizaje por observación (imitación) de estereotipos, al seleccionar modelos para sus anuncios, es importante tener en cuenta "la similitud percibida del modelo con el observador" Peter (2006), al considerarla implementación de este modelo de aprendizaje, para enseñar a los consumidores a quedarse con una marca determinada, podemos encontrar infinidad de casos, donde diferentes productos apoyan sus estrategias de comunicación,realizando este tipo de asociaciones; como por ejemplo festivales, obras de teatro, equipos deportivos, deportistas, cantantes, apoyo a causas benéficas; como ligas de cáncer, niños con síndrome de down; entre muchas otras, asociadas a la marca.

Específicamente esta asociación o estrategia de cambio actitudinal, los publicistas la han manejado a través del Patrocinio.

\subsection{El Patrocinio}

Definido como "una cuota en efectivo o en especie pagada a una propiedad (la cual puede ser un evento u organización deportiva, de entretenimiento o no lucrativa) a cambio del acceso al potencial mercantil explotable asociado con esa propiedad" William F. Arens. MichaelF. Weigold, Christian Arens (2008); de acuerdo con los autores, el patrocinio es una de las formas de mercadotécniacon más rápido crecimiento en la actualidad, que hoy en día abarca dos dimensiones; promoción de venta y relaciones públicas, y de la misma manera que se paga para patrocinar un programa, se puede hacer para financiar un deportista, una competencia deportiva, un festival o simplemente una exposición de arte, aluden que quizá este tipo de estrategia haya provenido de las compañías de tabaco y alcohol, pero su éxito al financiar deportes y eventos les han mostrado el camino a seguir, debido al éxito que han tenido.

Del mismo modo; se puede manejar la asociación con un deportista, un cantante o figura famosa, en donde se busca que características específicas de su comportamiento o personalidad; coincidan con la marca y de esta manera el consumidor se sienta motivado a la compraporque encuentra un espejo entre el producto y sus propias actitudes, aprendizajes o características de personalidad; además, los patrocinios tiene la capacidad de involucrar a los clientes potenciales y público involuntario y puede realzar de una forma pública y directa la imagen de la compañía o la marca.

Puede decirse que aproximadamente desde los años 80, los patrocinios son una herramienta en el mix de comunicación; empresas como Movistar, Coca Cola, Pastas la Muñeca, Pepsi, P\&G, Pony Malta; son sólo unos pocos ejemplos de empresas, que recurren a este tipo de estrategias.

A nivel comercial, los patrocinios son una estrategia que mueve grandes cifras; por ejemplo, en un artículo de uno de los diarios económicos más importantes en Colombia como es la República, en su publicaciónde Septiembre de 2013 dice: "desde 2012,cuando Néstor Pékerman tomó el mando de la Selección Colombia, varias marcas decidieron apostarle al fútbol nacional y sumarse a su equipo. La inversión total de los patrocinadores de la Selección suma ya más de US\$21 millones. Este espaldarazo tiene un costo-beneficio que les ha dejado excelentes cifras en ventas y reconocimientos a las marcas que acompañan a los 11 jugadores dirigidos por el argentino".

A través del patrocinio, las personas perciben una relación entre el acontecimiento y la marca patrocinadora. Así las diferentes imágenes, tanto del evento como de la marca, podrían ser ajustadas en la mente del consumidor (Dean(2002).

Las asociaciones mentales que realiza el consumidor acerca de la marca patrocinada, genera un efecto positivo entre los consumidores, que se traducirá en una determinada actitud y comportamiento hacia la marca patrocinadora Meenaghan(2001); por lo tanto,para que el patrocinio 
DanaMrńaLópez Célis

resulte efectivo, se debe buscar concordancia entre la marca patrocinadora y el acontecimiento.

Kahle y Homer (1985), fueron los primeros en examinar y proponer una hipótesis de formaempírica, acerca de cómo se produce este tipo de aprendizaje en las marcas; denominado; " match-up " en el contexto de la celebridad. Estos autores argumentaron y encontraron el apoyo a la idea de que la efectividad de la publicidad, se incrementa cuando la imagen de la celebridad, converge con la imagen del producto.

Existen investigaciones que se han realizado para evaluar el impacto o efectividad del patrocinio en las marcas, donde se ha encontrado material para demostrar que los patrocinios aportan a la construcción de marca, la mayoría de la literatura se encuentra relacionada con el patrocinio a equipos deportivos o deportistas.

La revisión de las diferentes investigaciones, coinciden en que solamente, se realizará esta transferencia; es decir la asociación de las características del deportista o equipo deportivo con la marca, si existe concordancia entre la imagen del producto y la imagen del equipo o deportista seleccionado. Generando un impacto positivo para la marca.

Gwinner, K. P., \&Eaton, J. (1999), realizaron una investigación acerca de La construcción de imagen de marca, a través del patrocinio de eventos deportivos denominado "La construcción de imagen de marca a través del patrocinio de eventos: El papel de la transferencia de imágenes", donde recalcan la importancia de hacer coincidir las características delos portavoces con las características de los productos. Los investigadores encontraron transferencia entre las características de personalidad del evento deportivo y la personalidad de marca del patrocinador - sponsorship. Identificaron asociaciones estadísticamente significativas entre el U.S. Open GolfChampionship y AcuraAutomobile, Indianapolis 500 Auto RaceyGoodyear Tires, World Cup Soccer y cigarrillos Camel.

Braunstein, I. R., \& Ross, S. D. (2010), hicieron un análisis acerca de las diferentes dimensiones de personalidad de marca en el deporte y sugieren revisar estas dimensiones para determinar si se encuentra relación entre estas características de personalidad deportiva y la marca,identificaron 6 dimensiones con un total de 41 características. Las dimensiones están determinadas como éxito, sofisticación, sinceridad, clásico, motivador y carácter fuerte, medidas a través del "brandpersonality in sport" (BPS). Dado este análisis, se debería revisar en un primer plano la coincidencia de alguna de estas dimensiones, con las características de la marca de acuerdo al objetivo que se persiga.

John Deane, Gareth Smith y Andrew Adams. (2003), Realizaron un estudio para identificar si existía relación entre las características de personalidad de la IBM y la Copa Ryder de golf. Evaluaron 5 factores: Sinceridad, Emoción, Competencia, Sofisticada y Robustes; los cuales ya habían sido desarrollados por (Aaker 1997), encontraron que un $46 \%$ de los participantes relacionaron a la Copa Ryder como una marca emocionante y $59 \%$ describió a IBM como una marca de competitiva, la característica de personalidad, en la cual los participantes sintieron que coincidían las dos marcas fueron;IBM como sincera y la Copa Rydercomo sincera con un $18 \%$ y $19 \%$ respectivamente.

Los anteriores resultados sustentan que IBM, debería apostarle a la construcción de su marca, para ser vista como más emocionante; de esta manera, aumentaría el ajuste entre la imagen de su marca y el evento, siendo más fuerte la transferencia de marca. IBM y Ryder Cup,comparten la característica de personalidad denominada "sinceridad" que se compone de los siguientes aspectos: los pies en la tierra, honesta, sana y alegre. En particular; la faceta de honestidad y carácter, pueden ser de importancia. Los autores concluyen que,en general no solamente se deben ver las características demográficas del evento, es importante revisar las coincidencias entre las características de personalidad y la imagen de marca.

Heere, B. (2010). En su investigación; “A New Approach to MeasurePerceived Brand PersonalityAssociationsAmongConsumers" tomó la escala de (Aaker 1997 "brandpersonality in sport" (BPS), para medir las características de personalidad de los equipos deportivos y apoyar a la construcción de la personalidad de marca, como una herramienta que ayuda a los gerentes de marca en este trabajo, y luego poder evaluar la concordancia; teniendo en cuenta que, los consumidores tienden a darle características humanas al producto y encontrarle un significado a este. 
Estas investigaciones, son algunos ejemplos de los trabajos que se han realizado en diferentes lugares del mundo y momentos, para analizar la importancia en la concordancia y transferencia de las imágenes de los equipos deportivos manejada a través del Sponsorship, sin encontrarse un gran número de investigaciones acerca del tema y casi inexistente en Latino América y específicamente en Colombia.

Como toda estrategia de Marketing en comunicación, el patrocinio o sponsorship busca generar una respuesta en el consumidor a nivel de conciencia, conocimiento, agrado, preferencia, convicción y compra.

Este mismo proceso puede resumirse en 3 respuestas "Informar, dar a conocer el producto y sus características; Persuadir, motivar a la compra y Recordar, en donde la publicidad se usa para mantener el producto y la marca en la mente del consumidor" (Lamb 2011).

\subsection{El Ambush Marketing}

Apalancados en el patrocinio, se encuentran otras marcas que no son directamente patrocinadores de eventos deportivos,pero ganan a través de la vinculación de la marca, a lo cual se le denomina, estrategia de emboscada o "ambush marketing".El ambush marketing, es uno de estos fenómenos que ha tenido un alto impacto en el mercado global.

De acuerdo con el artículo elaborado por Carlos Delvasto y Paola Cote, en su artículo titulado "El ambush marketing y el Mundial de Fútbol Brasil 2014: una reflexión a la luz de la regulación en Colombia" hacen un breve recorrido por esta definición; para realizar una reflexión desde el punto de vista legal, hacen en la introducción la precisión histórica acerca del término "ambush marketing"; el cual, es un anglicismo utilizado por primera vez por Jerry C. Welsh en los eventos deportivos de la década de los 80, para distinguir esta herramienta del arsenal de las compañías no patrocinadoras, para potencializar sus negocios y su imagen (Welsh, s.f.).

Sin embargo, para otros autores (Sandler y Shani, 1989) el ambush marketing, es aquella campaña o esfuerzo planeado por una organización para asociarse indirectamente con un evento, buscando adquirir al menos algún reconocimiento $o$ beneficios que se obtienen al ser patrocinador oficial. Según Meenaghan (1994), el ambush Marketing, consiste en aquella práctica de una empresa, a menudo un competidor, que captura la atención del público en torno al acontecimiento, desviando así la atención hacia sí misma y lejos del patrocinador. De acuerdo con Bean (1995) el ambush marketing, ocurre cuando aquellos que no son patrocinadores oficiales buscan ganancias o beneficios que solo están disponibles para estos.

En resumen, de acuerdo a Delvastoy Cote "son aquellas tácticas publicitarias que se presentan generalmente en eventos de gran reconocimiento, en donde terceros denominados ambushmarketers, aprovechan la popularidad y atención mediática de estos, para promocionar sus propios productos, pretendiendo adquirir beneficios que normalmente se le otorgarían a un patrocinador oficial, pero sin pagar las multimillonarias sumas en que incurren quienes legalmente pueden tener acceso a ciertos derechos exclusivos antes y durante la celebración del evento".

Un ejemplo muy claro de esta estrategia, fue la que usoasí Nike en los Juegos Olímpicos de Atlanta de 1996, cuando el patrocinador oficial fueReebok, o en la copa FIFA 2006, donde el patrocinador oficial fue Budweiser pero todo el posicionamiento se lo llevo Bavaria Breweris.

Podemos ver como en el reciente mundial de futbol; específicamente en Colombia, hubo muchas marcas que sin ser patrocinadores oficiales, aprovecharon el evento deportivo para realizar asociaciones de marca; es el caso de Davivienda, que sin ser patrocinador oficial, logró mejores posiciones a nivel de recordación de marca, a diferencia de marcas como Adidas, Cocacola o P\&G como patrocinadores oficiales, de acuerdo ainformación suministrada en una entrevista realizada a Johanna Paredes, Directora de cuenta en una de las centrales de medios más importantes para esta fecha.

Tanto los patrocinios como elambush marketing;son herramientas de comunicación,que persiguen un mismo objetivo; buscan la asociación de marca e identificación de estas con el evento o figura patrocinada; por lo tanto, la estrategia de comunicación va más allá dela inversión o herramientapublicitaria utilizada; puesto que vemos 
DanaMańaLópezCélis

como el ambush marketing, sin manejar directamente el patrocinio y con una inversión mucho menor al patrocinador, pueden generar mejores resultados; por consiguiente, juega un papel muy importantela forma como se maneja la comunicación; es decir el contenido y la coincidencia de las imágenes con el consumidor, llegando a representar una gran optimización en la inversión y capitalización de marca.

Para Mauricio Quintana, Gerente de mercadeo en Homecenter, patrocinador oficial de la selección Colombia, en entrevista concedida para la revista Marketing News en Noviembre de 2014, es claro que su estrategia fue jugársela por la selección Colombia. Dice que; lo único que todo patrocinador debe tener en cuenta, es que exista una verdadera relación entre lo que hace, comunica la marca, lo que ejecuta y lleva a cabo el patrocinado para buscar la identificación con la marca.

\section{Conclusiones:}

¿Patrocinio o ambush marketing?; la respuesta parecería obvia, puesto que se tienen mejores ventajas y oportunidades siendo el patrocinador, pero exige una mayor inversión a nivel publicitario, de acuerdo a la revisión teórica realizada, puede verse cómo el ambush marketing, con un buen manejo en cuanto a forma (contenido), puede generar iguales o mejores resultados, con una inversión menor.

De acuerdo a la anterior conclusión; puede decirse que, la forma en la comunicación juega un papel importante porque apoyada una buena estrategia de comunicación, el contenido "forma", puede lograr un buen impacto para la marca, más allá de ser patrocinador o ser "ambushmarketer", que muy posiblemente fue lo realizado por Davivienda en la campaña pasada del mundial, con los estereotipos de las situaciones que pueden pasarle a cualquier persona en diferentes situaciones, las cuales las vuelven jocosas, pero de una u otra forma las personas se sientes identificadas.

Como se dijo al principio del artículo, lo importante es que en el proceso de aprendizaje de consumo de marca, se busque una identificación del consumidor con la marca; por lo tanto, al patrocinar o trabajar con el ambush marketing, se debe realizar un buen análisis de las características del evento, famosos o estereotipo para patrocinar o pegársele "ambush marketing" y poder explotar estas características, asociándolas a la marca y a su vez que el consumidor a través del consumo de esta marca, se encuentre identificado con este estereotipo (aprendizaje por imitación) y haga la transferencia hacia la marca.Aumentando la probabilidad de generar fidelización de marca.

\section{Referencias:}

Braunstein, I. R., \& Ross, S. D. (2010). "Brand Personality in Sport: Dimension Analysis and General Scale Development. Sport Marketing Quarterly, Vol 19, No 1.

Dean D.H. (2002), "Associating the Corporation with a Charitable Event Through Sponsorship",Journal of Advertising, Vol. 31, No 4.

Deane, J., Smith, G., \& Adams, A. (2003). "Sports Sponsorship and Brand Personality -- The Ryder Cup Team and IBM". International Journal of Sports Marketing \& Sponsorship, Vol. 5, No. 3.

Delvasto Carlos y Paola Cote Tami. (2014) "El ambush marketing y el Mundial de Fútbol Brasil 2014: una reflexión a la luz de la regulación en Colombia" Revista Derecho Privado, Universidad de los Andes, Facultad de Derecho Vol 52.

Diario la República (2013; sept 09). “El espaldarazo a la Selección es de US\$21 millones"Disponible. [en línea]. Disponible en http://www.larepublica.co/negocio/elespaldarazo-la-selecci\%C3\%B3n-es-de-us21millones_58066

Farrelly, Francis, Quester, Pascale, Greyser, Stephen A. (2005). " Defending the Co-Branding Benefits of Sponsorship B2B Partnerships: The Case of Ambush Marketing", Journal of Advertising Research, Vol. 45.Fascículo 3.

Gwinner, K. P., \& Eaton, J. (1999). "Building Brand Image Through Event Sponsorship: The Role of Image Transfer". Journal Of Advertising, Vol. 28 No. 4.

Heere, B. (2010). "A New Approach to Measure Perceived Brand Personality Associations 
Among Consumers. Sport Marketing Quarterly". Vol.19 No 1.

Kahle, Lynn R. and Pamela M. Homer (1985), "Physical Attractiveness ofthe Celebrity Endorser: A Social Adaptation Persj) ective," c/ottrnai of Consumer Research, Vol 11 No 4.

Küster, I., Vila, N., Aldás, J., \& Rodríguez, C. (2009). "Efecto del Patrocinio de la Copa América en las percepciones de Luis Vuitton: una perspectiva internacional. (Spanish)". Universia Business Review. Vol 22.

Lamb, Ch., Hair, J. \& McDaniel, C. (2011). Marketing. (11 ed). México: Cengage.

Lambin, J (2004). Marketing Estrategico. Editorial Mc Graw Hill Interamnerican Editores, S.A.

Marketing News (2014; Nov 24) "Un producto con experiencia es el mix que toda marca debe adquirir [en línea]. Disponible en http://www.marketingnews.com.co/unproducto-con-experiencias-es-el-mix-quetoda-marca-debe-adquirir/

Meenaghan T. (2001), "Understanding sponsorship effects", Psychology \& Marketing, Vol. 18, No 2.

Peter, P. \&Olson, J. (2006). Comportamiento del Consumidor y Estrategia de Marketing. (7 ed.). México: McGraw-Hill.

Schiffman, L. \&Kanuk, L. (2010). Comportamiento del Consumidor. (10 ed). México: Pearson.

Stanton, W., Etzel, M. \&. Walker, B. (2007). Fundamentos de marketing. China: Mc Graw Hill.

Arens, W.Weigold, M.Arens,C. (2008). Publicidad(11 ed). México: McGraw-Hill. 